\title{
Introducing the Inaugural Chromatographia Virtual Issue: Macromolecular Separations
}

\author{
André M. Striegel ${ }^{1}$ \\ ๑) Springer-Verlag GmbH Germany, part of Springer Nature 2018
}

In contradistinction to their small-molecule counterparts, macromolecular separations are generally concerned less with issues of peak capacity and more with the determination of structure-property relations. The polymeric analytes themselves can possess dispersities along more than one physico-chemical dimension having, e.g., broad molar mass distributions as well as broad chemical composition and/or branching distributions. Multi-detector size-based separations, be they column or channel based, remain the preferred methods to obtain many of these relations.

Recently, all our subscribers received an e-mail (hopefully!) announcing the inaugural virtual issue of the journal. The topic of this virtual issue is macromolecular separation science. Highlighted therein are reviews and original papers published in the journal during the last 2 calendar years. Should you have missed this e-mail, or should our e-mailing have (unforgivably) missed you, our readers can still find out about some of the diverse work published in Chromatographia in 2016 and 2017 in the area of polymer chromatography through the eight papers constituting the virtual issue [1-8].

These publications exemplify the range of analytical techniques applicable to macromolecular separations, via original papers dealing with inverse gas chromatography [1], high-temperature multi-detector size-exclusion chromatography (SEC) [4], mass spectrometry and ion mobility separation [3], and asymmetric flow field-flow fractionation [5]; and in reviews dealing with off-line refractometry [7] and with SEC with on-line viscometry, in particular [2], and also covering hyphenated liquid chromatographic polymer analysis methods, in general [6].

The range of analytes studied employing these separation methods is also shown, in applications ranging from block copolymers [1, 3], to polyethylene [4], to nanoparticles [5], to polysaccharides $[2,7,8]$, to a variety of synthetic polymers $[2,6,7]$.

The papers included in the Virtual Issue on Macromolecular Separations will be accessible for free until the end of this month. We encourage all our readers to take a look at what the journal has published in this area. As contributions to the journal in this field continue to grow in $2018[9,10]$, we welcome your submissions.

\section{References}

1. Yazici O (2016) Chromatographia 79:355-362

2. Striegel AM (2016) Chromatographia 79:945-960

3. Shi C, Gerişlioğlu S, Wesdemiotis C (2016) Chromatographia 79:961-969

4. Boborodea A, Mirabella FM, O'Donohue C (2016) Chromatographia 79:961-969

5. Gigault J, Mignard E, El Hadri H, Grassl B (2017) Chromatographia 80:287-294

6. Uliyanchenko E (2017) Chromatographia 80:731-750

7. Striegel AM (2017) Chromatographia 80:989-996

8. Li X, Row KH (2017) Chromatographia 80:1161-1169

9. Brusotti G, Calleri E, Colombo R, Massolini G, Rinaldi F, Temporini C (2018) Chromatographia 81:3-23

10. Striegel AM, Haidar Ahmad IA (2018) Chromatographia $81: 823-827$
André M. Striegel

andre.striegel@nist.gov

1 National Institute of Standards and Technology,

Gaithersburg, USA 